\title{
Genetic structure of natural populations of the free-living amoeba, Naegleria lovaniensis. Evidence for sexual reproduction
}

\author{
P. PERNIN, A. ATAYA* \& M. L. CARIOU† \\ Faculté de Pharmacie, Laboratoire de Biologie Cellulaire, 3, rue du Pr Laguesse, 59045 Lille, *Faculté de Pharmacie, \\ Laboratoire de Parasitologie, 8 Avenue Rockefeller, 69373 Lyon Cedex et Haboratoire de Biologie et Génétique \\ Evolutives, Centre National de la Recherche Scientifique, 91198 Gif sur Yvette Cedex, France
}

\begin{abstract}
The genetic structure of two populations of Naegleria lovaniensis, comprising 71 isolates collected from the same local geographical area was investigated by isoenzyme analysis. Allelic variation at seven polymorphic enzymatic loci allowed identification of 45 distinctive genotype associations. Analysis of single locus variation reveals that most of them are close to Hardy-Weinberg equilibrium, which indicates segregation and free recombination between alleles. The recovery of a relatively high number of distinct genotypic associations (most of them being unique), and the absence of linkage disequilibrium between genotypes at the different loci also support the existence of recombination. Although we have no idea about the process involved, the results clearly indicate that genetic exchanges occur, at least occasionally, in natural populations of $N$. lovaniensis.
\end{abstract}

Keywords: amoeba, isozyme, genetic structure, sexual reproduction.

\section{Introduction}

While most species reproduce sexually, the existence of sexual processes seems exceedingly limited among the ancient and highly diversified group of Protozoa. Most of the Protozoa, including the major human parasites for which a clonal reproduction theory has been recently proposed (Tibayrenc et al., 1990), are considered to reproduce asexually. Amoebas are also generally considered to be asexual. Sexuality appears to be quite common only in Ciliates where complex sexual systems have been described for different species. In most cases, sexuality is not obligatory and sexual and asexual processes coexist within the same species (Sonneborn, 1957; Genermont, 1985, 1988). Curiously, genetic analysis of these species is virtually non-existent.

Because sexual reproduction has direct genetic consequences in terms of segregation and recombination, the use of genetic markers, such as enzymes, offers the possibility for detection of such processes and the analysis of the genetic structure of populations. For example, genetic exchanges have been reported on the basis of enzyme electrophoretic variations in a few cases for human parasites. Experimental demonstra- tions of genetic exchange (Jenni et al., 1986; Sternberg et al., 1988) and random mating have been made in the African Trypanosome, Trypanosoma brucei (Tait, 1980). Sexual recombination has been shown in Plasmodium falciparum (Walliker et al., 1987) and is also suspected in some Leishmania (Evans et al., 1987).

Among amoebas, genetic exchanges have been postulated only in two cases: Entamoeba histolytica, the agent of amoebic disentery in man (Sargeaunt, 1985; Sargeaunt et al., 1988) and Naegleria lovaniensis (Cariou \& Pernin, 1987).

The free-living amoebas of the genus Naegleria are common in freshwater and actually comprise six species, $N$. gruberi, $N$. jadini, $N$. lovaniensis, $N$. australiensis, $N$. andersoni and $N$. fowleri. The latter is recognized as pathogenic to man. It is the agent of an acute primary amoebic meningoencephalitis while pathogenicity of another species, $N$. australiensis, has only been recognized experimentally. $N$. lovaniensis, primarily identified as 'a non-pathogenic variant' of $N$. fowleri (De Jonckheere \& Van De Voorde, 1977) shares with that species several biological characteristics (thermophily, capacity of axenization) and antigenic cross-reactivity (Stevens et al., 1980) but appears, in contrast, to 
be genetically well differentiated (Pernin et al., 1985). However, these two species are phylogenetically closely related (Pernin et al., 1985; Clark et al., 1989).

Diploidy of most Naegleria species is strongly suggested by the occurrence of heterozygous electrophoretic patterns for a number of enzymes (Cariou \& Pernin, 1987; Adams et al., 1989) although both the small size of chromosomes and their high number have prevented any caryotype analysis. Recent studies, using pulsed-field gel electrophoresis, estimate the chromosome number to be about 23 for $N$. gruberi with variations between strains but the ploidy of the species remains uncertain (Clark, 1990; De Jonckheere, 1989; Clark et al., 1990). On the other hand, as far as we know, nothing is known about the genetic structure of natural populations in these amoeba species and our previous data on $N$. lovaniensis relate only to a few laboratory strains (Cariou \& Pernin, 1987).

In this study, enzyme electrophoresis was applied to 71 isolates of $N$. lovaniensis collected from a single geographical area, thus offering opportunity for genetic exchange, to address the following points. (i) Does segregation exist at individual loci? (ii) Are recombination and random mating the usual features within the species? (iii) Our data may also shed some light onto the genetic structure of natural $N$. lovaniensis populations.

\section{Materials and methods}

\section{Strains}

As a part of a systematic biological water surveillance, 71 strains of $N$. lovaniensis were isolated from different sites of two districts along the course of the Moselle river (France) in 1987. Fifty-eight strains originated from the northern down-stream river near the Luxemburg frontier (Cattenom population) and 13 were isolated from the up-stream river, $50 \mathrm{~km}$ apart, in the vicinity of Metz city (Moselle South population). The thermophilic Naegleria strains were isolated by water filtration and incubation of inverted membranes at $44^{\circ} \mathrm{C}$ for several days on a gelose surface overlaid with a thin pellicle of $E$. coli (non-nutrient agar: NNA). Recognition of Naegleria genus was achieved by microscopic criteria and confirmed by the ability of trophozoits to transform into flagellates when suspended in distilled water. Species identification was supported by the analysis, in $\mathrm{pH}$ gradient 4-6.5, of malic enzyme, which has previously been proved to be a diagnostic locus (Pernin et al., 1985).

The strains were grown axenically on SCGYEM liquid medium or monoxenically on gelose NNA. Six axenic reference strains of $N$. lovaniensis were also used for comparisons.

\section{Isoenzymatic study}

The axenic and monoxenic strains were harvested, as previously described (Pernin \& Grelaud, 1989) and then lysed by a single freeze-thaw cycle. The cellular extracts were then submitted to isoelectric focusing. For all the enzymes assayed an $E$. coli control (prepared in the same manner as cellular extracts) was included to detect possible bacterial isozymes. No allozyme differences were detected between axenic and monoxenic cultures of the same isolate (Fig. 1).

The following five polymorphic enzymes in $N$. lovaniensis were scored: malic enzyme (ME), superoxide dismutase (SOD), leucine aminopeptidase (LAP), 6-phosphogluconate dehydrogenase (6-PGD), which appeared encoded by a single locus, and phosphoglucomutase (PGM) involving three separate loci. Alleles were numbered according to their $\mathrm{p} I$ from the most cathodic to the most anodic and were consistent with our previous designations (Pernin et al., 1985). Allele frequencies at the highly polymorphic Lap1 locus, which involves a null allele in Cattenom population, were estimated by using the EM Algorithm also called 'Gene Counting' (Weir, 1990). Because the expected values for some genotypic classes were small, departures from expected Hardy-Weinberg proportions of genotypes could not be tested using classical goodness-of-fit procedures without extensive pooling. As a consequence, an exact test for multiple alleles (Louis \& Dempster, 1987), suitable when expected frequencies are low and considered to be better than standard methods when the probability of drawing a given sample is near the $\alpha$ level of significance, was used to test the hypothesis of Hardy-Weinberg equilibrium.

Nei's standard genetic distances (1972) were computed to assess the extent of genetic divergence among isolates of $N$. lovaniensis. In this case, because each isolate kept in laboratory conditions consisted of a population of identical cells, allele frequencies were only $0,0.5$ or 1 . Another multilocus genetic comparison was also achieved by ordinating the isolates in three-dimensions with a Centered Data Analysis (Lefebvre, 1976) performed from the same matrix of allele frequencies.

\section{Results}

A genetic interpretation of electrophoretic banding patterns was made in the usual way and by comparison with previously observed genotypes. Single-banded phenotypes indicate isolates that are homozygous while multiple banded ones correspond to heterozygotes (Fig. 1). In all cases heterozygote banding patterns are consistent with the quaternary structure 

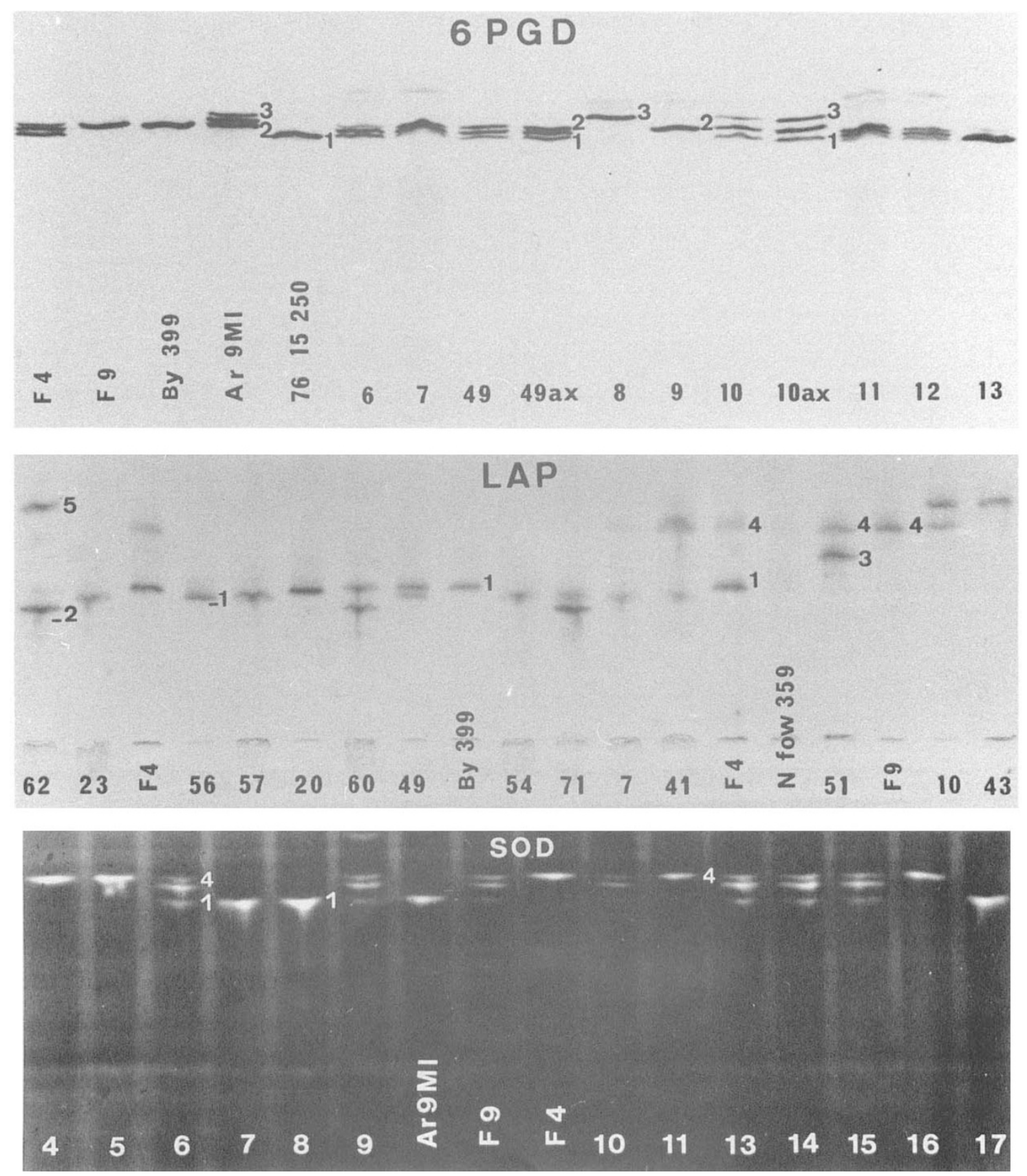

Fig. 1 Acrylamide gel isofocusing patterns of three enzymes in Naegleria lovaniensis. Moselle isolate numbers and reference strains are labelled on the gels. Different alleles identified at $6 \mathrm{Pgd}$, Lap1 and Sod2 loci are numbered according to their mobility. Homozygotes (single banded) and heterozygotes (double or three banded) are clearly distinguished. The patterns of isolates in either axenic or monoxenic conditions are identical for 6Pgd (Isolates 49 and 10). N. fow. 359 has low Lapl activity, particularly in the $\mathrm{pH}$ gradient $4-6.5$ used here, thus it appears to have no activity.

known for the enzymes involved. The finding of additional heterozygous phenotypes support once more the diploidy of the species $N$. lovaniensis.

The two alleles previously identified at $M e$, Sod2, Pgm2 and Pgm3 loci (Pernin et al., 1985) were observed and, as expected from a more extensive survey, some new alleles were also found. All together three alleles are now known at the 6Pgd and Pgml loci, and seven, including a null allele, at Lapl (Fig. 1).

Allele frequencies at each locus in the two popula- 
Table 1 Allele frequencies at seven polymorphic loci in two natural populations of Naegleria lovaniensis. A $\chi^{2}$ test for homogeneity was calculated. Observed and expected genotype numbers are given. An exact test (Louis \& Dempster, 1987) is used to test the Hardy-Weinberg equilibrium. The multinomial probability of obtaining the sample from such a population is calculated. The hypothesis is rejected if the cumulative probability is less than 0.05

\begin{tabular}{|c|c|c|c|c|c|c|c|c|c|c|}
\hline \multirow[b]{3}{*}{ Locus } & \multirow[b]{3}{*}{ Allele } & & & & \multicolumn{6}{|c|}{ Genotypes } \\
\hline & & \multicolumn{3}{|c|}{ Allele frequencies } & \multicolumn{3}{|l|}{ Cattenom } & \multicolumn{3}{|l|}{ Moselle } \\
\hline & & $\begin{array}{l}\text { Cattenom } \\
(58)\end{array}$ & $\begin{array}{l}\text { Moselle } \\
\text { (13) }\end{array}$ & $\chi^{2}$ & $\begin{array}{l}\text { Number } \\
\text { possible }\end{array}$ & $\begin{array}{l}\text { Number } \\
\text { observed }\end{array}$ & $\begin{array}{l}\text { Exact } \\
\text { test }\end{array}$ & $\begin{array}{l}\text { Number } \\
\text { possible }\end{array}$ & $\begin{array}{l}\text { Number } \\
\text { observed }\end{array}$ & $\begin{array}{l}\text { Exact } \\
\text { test }\end{array}$ \\
\hline \multirow[t]{2}{*}{$M e$} & 1 & 0.026 & 0.077 & \multirow[t]{2}{*}{ ns } & \multirow[t]{2}{*}{3} & \multirow[t]{2}{*}{2} & 1 & \multirow[t]{2}{*}{3} & \multirow[t]{2}{*}{2} & 1 \\
\hline & 2 & 0.974 & 0.923 & & & & ns & & & ns \\
\hline \multirow[t]{2}{*}{$\operatorname{Sod} 2$} & 1 & 0.241 & $0.615^{* * *}$ & & \multirow[t]{2}{*}{3} & \multirow[t]{2}{*}{3} & 0.481 & \multirow[t]{2}{*}{3} & \multirow[t]{2}{*}{3} & 1 \\
\hline & 4 & 0.759 & 0.385 & & & & ns & & & ns \\
\hline \multirow[t]{3}{*}{$6 P g d$} & 1 & 0.552 & $0.346^{* *}$ & & \multirow[t]{3}{*}{6} & \multirow[t]{3}{*}{5} & 0.681 & \multirow[t]{3}{*}{6} & \multirow[t]{3}{*}{4} & \multirow[t]{3}{*}{0.045} \\
\hline & 2 & 0.397 & 0.346 & & & & ns & & & \\
\hline & 3 & 0.052 & 0.308 & & & & & & & \\
\hline \multirow[t]{3}{*}{ Pgm1 } & 1 & 0.888 & $0.692^{* *}$ & & \multirow[t]{3}{*}{3} & \multirow[t]{3}{*}{2} & 1 & \multirow[t]{3}{*}{6} & \multirow[t]{3}{*}{4} & 0.420 \\
\hline & 2 & 0.112 & 0.269 & & & & $\mathrm{~ns}$ & & & ns \\
\hline & 3 & - & 0.038 & & & & & & & \\
\hline \multirow[t]{2}{*}{$\operatorname{Pgm} 2$} & 1 & 0.853 & $0.692^{* *}$ & & \multirow[t]{2}{*}{3} & \multirow[t]{2}{*}{2} & 0.590 & \multirow[t]{2}{*}{3} & 3 & 0.508 \\
\hline & 3 & 0.147 & 0.308 & & & & ns & & & ns \\
\hline $\operatorname{Pgm} 3$ & 1 & 0.879 & 0.769 & ns & 3 & 3 & 0.174 & 3 & 2 & 1 \\
\hline & 2 & 0.121 & 0.231 & & & & ns & & & ns \\
\hline Lapl & -2 & 0.129 & $0.038^{* * * *}$ & & 22 & 12 & nc & 15 & 6 & 0.025 \\
\hline & -1 & 0.192 & 0.115 & & & phenotypes & & & & \\
\hline & 1 & 0.183 & 0.269 & & & & & & & \\
\hline & 3 & 0.009 & $\bar{a}$ & & & & & & & \\
\hline & $\begin{array}{l}4 \\
5\end{array}$ & $\begin{array}{l}0.234 \\
0.174\end{array}$ & $\begin{array}{l}0.462 \\
0.115\end{array}$ & & & & & & & \\
\hline & null & 0.117 & - & & & & & & & \\
\hline
\end{tabular}

$\mathrm{nc}=$ Not calculated, too much computing time required.

tions are given in Table 1. Clearly the two populations share the same alleles except a few rare ones $\left(P g m 1^{3}\right.$, $L_{\text {Lapl }}{ }^{3}$ and Lap $\left.1^{\text {null }}\right)$ but some individual loci differ significantly for allelic frequencies (6Pgd and Sod2). A chi-square test for homogeneity over all loci was significant $\left(\chi^{2}=100.50, P<10^{-4}\right)$, therefore the two populations are considered separately.

\section{Hardy-Weinberg equilibrium at individual loci}

Expected genotypic numbers were calculated from allele frequencies for each of the seven polymorphic loci assuming Hardy-Weinberg equilibrium (Table 1). Most, if not all, of the possible genotypes are detected at the various loci. The missing genotypes are those that involve rare alleles. The only exception is Lap1 where a high number of alleles occur. The data strongly suggest that Mendelian segregation operates at these loci.
The genotypic frequencies observed at the segregating loci support Hardy-Weinberg expectations as determined by the exact test performed for each population. The statistic is given in Table 1. Equilibrium is likely for 6Pgd (although close to significance in Moselle South population), Sod2, the three Pgm loci and $\mathrm{Me}$. However, for loci with an allele near fixation, such as $\mathrm{Me}$, it is difficult to detect deviations from HardyWeinberg proportions when they are not large. The hypothesis cannot be accepted for the highly polymorphic Lap1 locus in both populations (even where it was not achieved by calculation the cumulative probability was low suggesting that the test would be significant for Cattenom population). Some heterozygotes are in excess while others are under-represented or totally missing. Nevertheless, the number of observed genotypes (15) is not far from the theoretically expected number (22 instead of 28 because of the existence of a null allele) and the discrepancies may be 
explained by the high number of alleles and the small sample size investigated. All together the data support the hypothesis of random assortment of alleles at individual loci.

\section{Genetic recombination and linkage equilibrium}

If reproduction is clonal the genotypic association present in each isolate would be transmitted intact, generating strong linkage disequilibrium between genotypes at different loci. In contrast, under sexual reproduction, random assortment between genotypes has to be expected.

The comparison of the multilocus genotypic structure in the 71 isolates for the seven loci reveals 45 distinctive genotypic associations (GA), which are listed in Table 2. Most are unique, 30 out of 45 , and the maximum number of identical isolates is six. The number of genotypic differences between these 45 pairwise GA is often high, from 3 to 6 , indicating that there is no correlation between homozygosity or heterozygosity at one locus and the condition at other loci. They resemble randomly assorted genotypes. The five heterozygous isolates $M e^{1 / 2}$ (isolates $3,36,67$ from Cattenom and 7, 41 from Moselle South) are demonstrative with regard to that point: they all have different genotypic profiles (Table 2).

\section{Genetic structure analysis of $\mathrm{N}$. lovaniensis}

Nei's genetic distances, calculated among the 45 distinct $\mathrm{GA}$ on the basis of allele frequencies, provide an estimation of genetic heterogeneity within the species. The minimum distance value is 0.044 while the maximum is as high as unity indicating substantial genetic differentiation among extreme isolates. Most of the isolates show an intermediate level of differentiation (Fig. 2). Clearly these values cannot be compared to those published before (Pernin et al., 1985) because they are based on a restricted set of loci ( 7 versus 23 ) and all are polymorphic. Consequently the present estimates are largely overestimated.

To investigate further the genetic structure of the species, we employed a multivariate analysis of allele frequencies of each of the 45 distinct GA in a plot of the three first axis, which explains 53 per cent of total variability. The centered data analysis reveals a wide spatial distribution of the strains without any clear-cut group (Fig. 3). Moreover, isolates belonging to the Moselle South population are regularly interspersed among Cattenom population indicating that they are well within the range of genetic variability of the former population.

\section{Discussion}

\section{Genetic variation within N. lovaniensis}

Enzyme polymorphisms among $N$. lovaniensis, based on phenetic comparisons, have been reported several times during the last decade (Nerad \& Daggett, 1979; De Jonckheere, 1982; Moss et al., 1988). However, unexpectedly, restriction endonuclease digestion of total genomic DNA (De Jonckheere, 1987) and analysis of ribosomal DNA plasmid restriction patterns (Clark et al., 1989) failed to demonstrate any difference among $N$. lovaniensis strains. Our present data reveal substantial genetic variation among isolates belonging to the species $N$. lovaniensis, thus confirming our previous results (Pernin et al., 1985). These data are also consistent with those recently published by Adams et al. (1989), both studies involving genetic interpretation of electrophoregrams.

Variation in allele frequencies at two polymorphic loci indicates some local differentiation between the two populations located $50 \mathrm{~km}$ apart. This may be partially due to the lower number of isolates collected in the Moselle South population and their scarcity but also because these amoebas may be geographically restricted. In fact they live fixed on various substrates such as pilings, dead wood, stones, plants, etc., and they move by crawling along the substrate. However, both populations share the same predominant alleles indicating gene flow between them, and probably along the stream. Even if they are fixed, amoebas may detach from their substrate and are probably able to migrate passively over relatively long distances.

The extensive genetic variation between individuals within the species and the similarity between the two populations are illustrated by the Centered Data Analysis. Moreover, the reference strains, which have broad geographical origins (USA, France and Belgium), are also well within the range of genetic variability of Moselle populations when they are plotted in the same analysis. This suggests that the French populations may be representative of the genetic structure of the whole species despite its large present geographical distribution. Furthermore, a common origin for all $N$. lovaniensis might be hypothesized as well as a possible recent dispersion throughout the world. However, both hypotheses have to be confirmed by more extensive analysis of various geographical populations.

\section{Evidence for sexual reproduction}

Our analysis of a large number of isolates for several polymorphic loci shows that genotypic frequencies at 
Table 2 Genotypic associations at seven polymorphic loci in 71 isolates of Naegleria lovaniensis from natural populations and six reference strains

\begin{tabular}{|c|c|c|c|c|c|c|c|}
\hline \multirow[b]{2}{*}{ Isolate numbers } & \multicolumn{7}{|c|}{ Enzymatic loci } \\
\hline & $M e$ & Sod & Lapl & $P g m l$ & $\operatorname{Pgm} 2$ & $P g m 3$ & $6 P g d$ \\
\hline \multicolumn{8}{|l|}{$\begin{array}{l}\text { Moselle south } \\
\text { population }\end{array}$} \\
\hline 7 & $1 / 2$ & 1 & $-1 / 4$ & $1 / 2$ & 1 & $1 / 2$ & $1 / 2$ \\
\hline 9 & 2 & $1 / 4$ & 4 & $1 / 2$ & 3 & 1 & 2 \\
\hline 15 & 2 & 4 & 4 & 2 & $1 / 3$ & 1 & $1 / 2$ \\
\hline 16 & 2 & 1 & $1 / 5$ & 1 & 1 & $1 / 2$ & $1 / 3$ \\
\hline 41 & $1 / 2$ & $1 / 4$ & $-1 / 4$ & $1 / 2$ & 1 & 1 & $1 / 2$ \\
\hline 42 & 2 & $1 / 4$ & 1 & 1 & 3 & 1 & $1 / 2$ \\
\hline 68 & 2 & 4 & 4 & 1 & $1 / 3$ & 1 & $1 / 3$ \\
\hline 69 & 2 & 1 & 4 & 1 & 1 & 1 & $1 / 2$ \\
\hline 70 & 2 & $1 / 4$ & $1 / 4$ & 1 & 1 & $1 / 2$ & 2 \\
\hline 71 & 2 & $1 / 4$ & $-2 /-1$ & $1 / 2$ & $1 / 3$ & $1 / 2$ & $1 / 3$ \\
\hline 72 & 2 & $1 / 4$ & $1 / 4$ & $2 / 3$ & $1 / 3$ & 1 & $1 / 3$ \\
\hline 8,17 & 2 & 1 & $1 / 5$ & 1 & 1 & $1 / 2$ & 3 \\
\hline \multicolumn{8}{|l|}{ Cattenom population } \\
\hline 3 & $1 / 2$ & $1 / 4$ & 1 & 1 & 1 & 1 & 2 \\
\hline 4 & 2 & 4 & $-2 / 4$ & $1 / 2$ & $1 / 3$ & 1 & 2 \\
\hline 6 & 2 & $1 / 4$ & 4 & 1 & $1 / 3$ & 1 & $1 / 2$ \\
\hline 11 & 2 & 4 & 4 & $1 / 2$ & 1 & 1 & $1 / 2$ \\
\hline 20 & 2 & $1 / 4$ & 1 & 1 & 1 & $1 / 2$ & $1 / 2$ \\
\hline 22 & 2 & 4 & $-2 / 4$ & 1 & 1 & 1 & 2 \\
\hline 28 & 2 & 4 & 4 & 1 & 1 & 1 & $1 / 2$ \\
\hline 29 & 2. & 4 & 4 & $1 / 2$ & 1 & $1 / 2$ & 1 \\
\hline 33 & 2 & 4 & $-1 / 1$ & $1 / 2$ & 1 & 1 & 1 \\
\hline 36 & $1 / 2$ & 4 & $-2 / 4$ & 1 & 1 & 1 & 1 \\
\hline 40 & 2 & $1 / 4$ & 4 & $1 / 2$ & 1 & 1 & 2 \\
\hline 44 & 2 & 4 & 5 & 1 & $1 / 3$ & 1 & 1 \\
\hline 51 & 2 & $1 / 4$ & $3 / 4$ & 1 & 1 & 1 & 1 \\
\hline 61 & 2 & $1 / 4$ & $4 / 5$ & 1 & $1 / 3$ & 1 & 2 \\
\hline 62 & 2 & 1 & $-2 / 5$ & 1 & 1 & 1 & $1 / 3$ \\
\hline 63 & 2 & 4 & $4 / 5$ & 1 & 1 & 1 & $1 / 2$ \\
\hline 65 & 2 & 4 & 4 & 1 & 1 & 1 & 1 \\
\hline 66 & 2 & 4 & 4 & 1 & 1 & $1 / 2$ & $1 / 2$ \\
\hline 67 & $1 / 2$ & 1 & $-2 / 4$ & 1 & $1 / 3$ & $1 / 2$ & $1 / 3$ \\
\hline 2,10 & 2 & $1 / 4$ & $4 / 5$ & 1 & 1 & $1 / 2$ & $1 / 3$ \\
\hline 5,19 & 2 & 4 & $-2 / 1$ & 1 & 1 & 1 & $1 / 2$ \\
\hline 18,21 & 2 & 4 & 4 & 1 & 1 & $1 / 2$ & 2 \\
\hline 27,48 & 2 & 4 & 1 & $1 / 2$ & 1 & 1 & $1 / 2$ \\
\hline 35,37 & 2 & $1 / 4$ & $-2 / 4$ & 1 & 1 & 2 & 2 \\
\hline 38,39 & 2 & $1 / 4$ & $-2 / 4$ & 1 & 1 & 1 & $2 / 3$ \\
\hline 43,46 & 2 & 4 & 5 & 1 & $1 / 3$ & $1 / 2$ & 1 \\
\hline 52,59 & 2 & $1 / 4$ & null & 1 & $1 / 3$ & 1 & 1 \\
\hline 55,58 & 2 & 4 & $-2 / 1$ & 1 & 1 & 1 & 2 \\
\hline 60,64 & 2 & $1 / 4$ & $-2 / 1$ & 1 & 1 & 1 & $1 / 2$ \\
\hline $1,12,25,26$ & 2 & $1 / 4$ & $1 / 4$ & 1 & $1 / 3$ & 1 & $1 / 2$ \\
\hline $13,14,24,34$ & 2 & $1 / 4$ & $4 / 5$ & 1 & $1 / 3$ & 1 & 1 \\
\hline $23,50,54,56,57$ & 2 & 4 & -1 & 1 & 1 & 1 & 1 \\
\hline $30,31,32,47,49,53$ & 2 & 4 & $-1 / 1$ & $1 / 2$ & 1 & 1 & $1 / 2$ \\
\hline \multicolumn{8}{|l|}{ Reference strains } \\
\hline Ar9Ml (USA) & 2 & 1 & 4 & 1 & 1 & 1 & $2 / 3$ \\
\hline BY399 (France) & $1 / 2$ & $1 / 4$ & 1 & 1 & 1 & 1 & 2 \\
\hline F4 (Belgium) & 2 & 4 & $1 / 4$ & 2 & 1 & 1 & $1 / 2$ \\
\hline F9 (Belgium) & 2 & $1 / 4$ & 4 & 1 & 1 & 1 & 2 \\
\hline 76.78.S9 (Belgium) & 2 & 4 & $1 / 4$ & 1 & 1 & $1 / 2$ & $1 / 2$ \\
\hline 76.15.250 (Belgium) & 2 & 4 & 4 & 1 & 1 & $1 / 2$ & 1 \\
\hline
\end{tabular}


Fig. 2 Distribution of Nei's genetic distances between the 45 pairwised genotypic associations found in $N$.

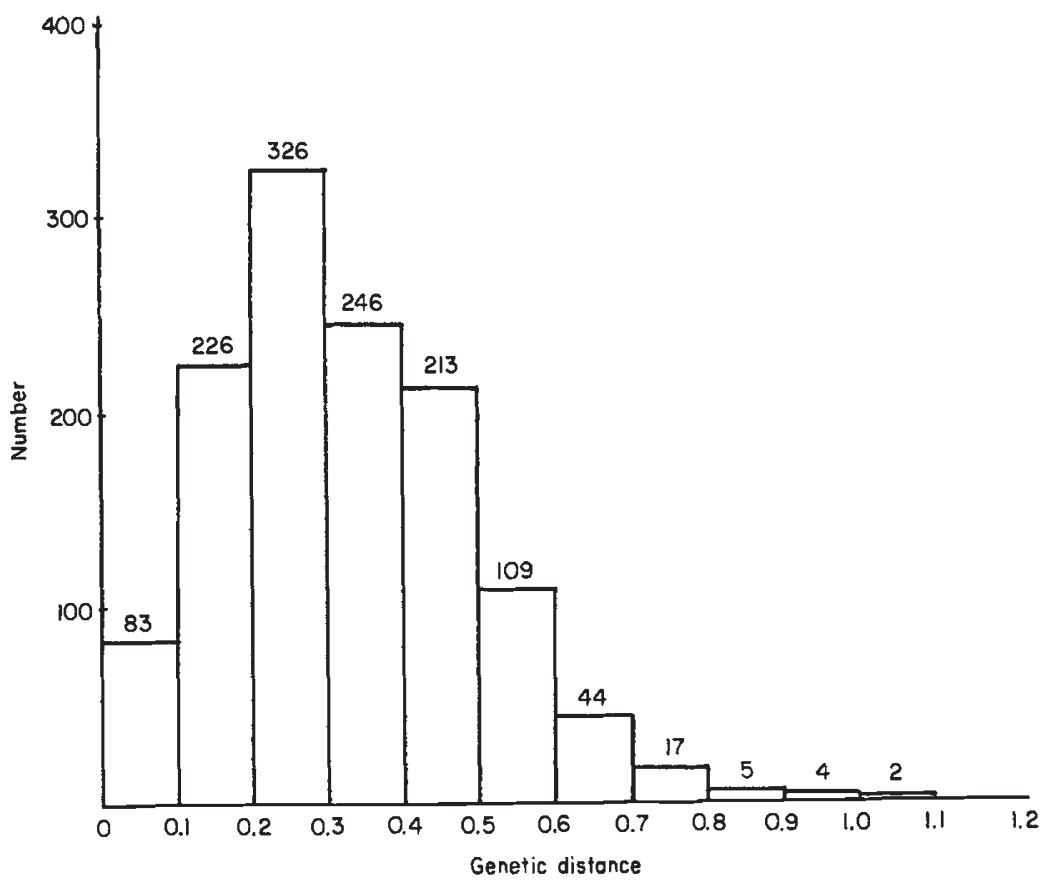
lovaniensis (seven polymorphic loci).

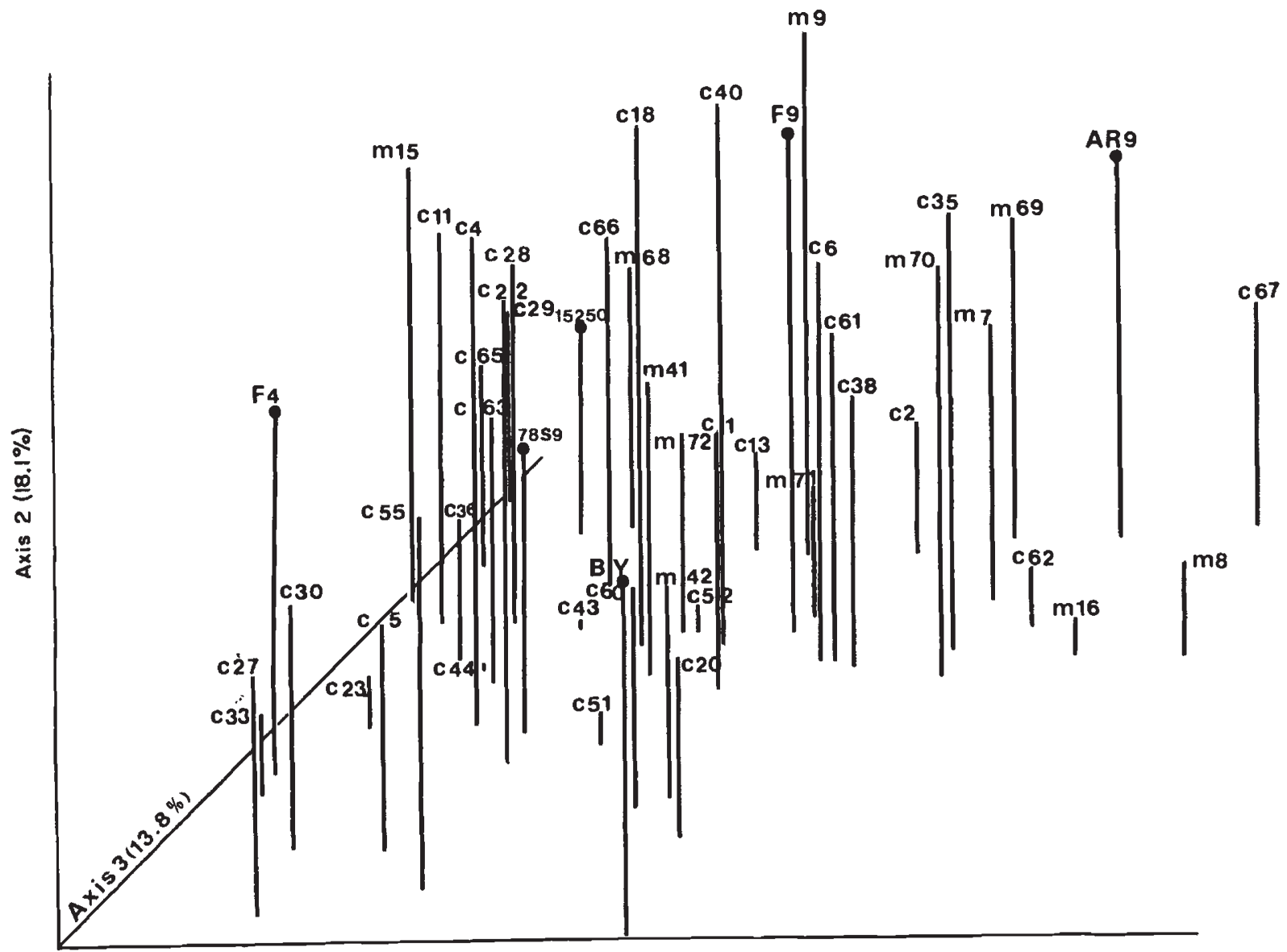

Axis $1(20.9 \%)$

Fig. 3 Centered data analysis based on allele frequencies for each of the $45 \mathrm{GA}$ of $N$. lovaniensis. Plotting of isolates from Cattenom $(\mathrm{c})$, Moselle South $(\mathrm{m})$ and reference strains $(\bullet)$ on the three first axes ( 53 per cent of total variability) indicate Substantial variability among the species and the absence of any clear-cut group. Isolate C 3 is identical to reference strain BY399 and only the latter strain is indicated. 
individual loci are close to Hardy-Weinberg equilibrium. This result provides convincing evidence for Mendelian segregation and random association of alleles at each locus. Moreover, despite some genetic differentiation between the two populations, when the 71 isolates are pooled, Hardy-Weinberg expectations are still met. This strengthens the argument in favour of genetic recombination in $N$. lovaniensis. In addition we have been unable to detect linkage disequilibrium between the different loci.

The absolute stability of enzymatic patterns in laboratory conditions over $\sim 3$ years for the $N$. lovaniensis Moselle isolates and 7 years for the reference strains indicates that asexual reproduction is the rule in the laboratory while sexual reproduction may be limited to field conditions. In contrast, genetic exchanges have only been detected under experimental conditions for Entamoeba histolytica (Sargeaunt, 1985).

Even in the wild, where populations approximate Hardy-Weinberg equilibrium, sexual reproduction may not be a regular process (Smith \& Fraser, 1976). In cyclic parthenogens like Daphnia species (Crustacean, Cladocere), the alternation of parthenogenetic and sexual generations, depending upon environmental conditions, is sufficient to provide genotypic frequencies close to Hardy-Weinberg expectations at several loci (Hebert, 1974). It has been shown that Hardy-Weinberg equilibrium was recovered at the first sexual generation even after a long parthenogenetic reproduction period (Hebert, 1987). In contrast, obligate parthenogenetic populations usually show large deviations (Hebert \& Crease, 1983).

All the data indicate random exchange among genotypes and we have to conclude that this species experiences some form of sexual reproduction, at least occasionally, and probably not infrequently in natural conditions.

In any species, sexual processes involve karyogamy to keep the number of chromosomes constant whether the species is haploid or diploid. Amoeba cells forming pairs and containing two or several nuclei have been described (Goodfellow et al., 1974). The authors suggest that if a sexual process does take place it is likely to occur between morphologically similar cells involving some form of mating type. However, if adherence of one cell to another is a prerequisite to sexual process it is not in itself sufficient to conclude that real genetic exchanges occur. All the Naegleria species possess a single nucleus and nothing similar to nuclear fusion has ever been reported.

Although the nature of sexual processes in $N$. lovaniensis, in particular, and amoebas in general, remain completely unknown, the problem of sexual and asexual processes is of considerable basic biological significance. The discovery of genetic recombination, even if it is only occasional, makes sense with regard to the specific status of $N$. lovaniensis which appears to be at present the only 'true species' among the Naegleria.

\section{Acknowledgements}

We are grateful to Mrs P. Gallet for technical assistance and to J. P. Gauthier for expert help with computer analysis. This work was supported by a grant from Electricité de France, Département Etudes et Recherches.

\section{References}

ADAMS, M., ANDREWS, R. H., ROBINSON, B., CHRISTY, P., BAVERSTOCK, P. R., DOBSON, P. J., AND BLACKLER, S. J. 1989. A genetic approach to species criteria in the amoeba genus Naegleria using allozyme electrophoresis. Int. J. Parasitol., 19, 823-834.

CARIOU, M. L. AND PERNIN, P. 1987. First evidence for diploidy and genetic recombination in free-living Amoebae of the genus Naegleria on the basis of electrophoretic variation. Genetics, 115, 265-270.

ClARK, C. G. 1990. Genome structure and evolution of Naegleria and its relatives. J. Protozool., 37, 2S-6S.

CLARK, C. G., CROSS, G. A. M. AND DE JONCKHEERE, J. F. 1989. Evaluation of evolutionary divergence in the genus Naegleria by analysis of ribosomal DNA plasmid restriction patterns. Mol. Biochem. Parasitol., 34, 281-296.

ClARK, C. G., LAI, E. Y., FUlTON, C. AND CROSS, G. A. M. 1990. Electrophoretic karyotype and linkage groups of the Amoebo flagellate Naegleria gruberi. J. Protozool., 37, 400-408.

DE JONCKHEERE, J. F. 1982. Isoenzyme patterns of pathogenic and nonpathogenic Naegleria sp. using agarose isoelectric focusing. Ann. Microbiol., 133, 319-342.

DE JONCKHEERE, J. F 1987. Characterization of Naegleria species by restriction endonuclease digestion of whole-cell DNA. Mol. Biochem. Parasitol., 24, 55-66.

DE JONCKHEERE, J. F. 1989. Variation in electrophoretic karyotypes among Naegleria sp. Parasitol. Res., 76, 55-62.

DE JONCKHEERE, J. F. AND VAN DE VOORDE, M. 1977. Comparative study of six strains of Naegleria with special reference to nonpathogenic variants of Naegleria fowleri. J. Protozool., 24, 304-309.

EVANS, D. A., KENNEDY, W. P. K., ELBIHARI, S., CHAPMAN, C. J., SMITH, V. AND PETERS, w. 1987. Hybrid formation within the genus Leishmania? Parassitologia, 29, 165-173.

GENERMONT, J. 1985. Les systèmes d'incompatibilité sexuelle chez les Protozoaires. Bull. Soc. Zool. Fr., 110, 261-267.

GENERMONT, J. 1988. Quelques systèmes de croisement chez les Protozoaires; conséquences génétiques; implications biologiques. Colloque Méribel INRA "Heterosis et consanguinité", INRA, Paris. 
Goodfellow, L. P., Belcher, J. H. AND PaGe, F. C. 1974. A light and electron microscopical study of Sappinia diploidea, a sexual amoeba. Protistologica, 10, 207-216.

HEBERT, P. D. N. 1974. Enzyme variability in natural populations of Daphnia magna. II. Genotypic frequencies in permanent populations. Genetics, 77, 323-334.

HEBERT, P. D. N. 1987. Genotypic characteristics of the Cladocera. Hydrobiologia, 145, 183-193.

HEBERT, P. D. N. AND CREASE, T. J. 1983. Clonal diversity in populations of Daphnia pulex reproducing by obligate parthenogenesis. Heredity, 51, 353-369.

JENNI, L., MARTI, S., SCHWEIZER, J., BETSCHART, B., LE PAGE, R. W. F., WELLS, J. M., TRAIT, A., PAINDAVOINE, P., PAYS, E. AND STEINERT, M. 1986. Hybrid formation between African trypanosomes during cyclical transmission. Nature, 322, 173-175.

LEFEBVRE, J. 1976. Introduction aux analyses statistiques multidimensionelles. Masson (ed.), Paris.

LOUIS, E. J. AND DEMPSTER, E. R. 1987. An exact test for HardyWeinberg and multiple alleles. Biometrics, 43, 805-811.

MoSS, D. M., BRANDT, F. H., MATHEWS, H. M. AND VISVESVARA, G. S. 1988. High-resolution polyacrylamide gradient gel electrophoresis (PGGE) of isoenzymes from five Naegleria species. J. Protozool., 35, 26-31.

NEl, M. 1972. Genetic distance between populations. Am. Nat., 106, 283-292.

NERAD, T. A. AND DAGGETT, P. M. 1979. Starch gel electrophoresis: an effective method for separation of pathogenic and nonpathogenic Naegleria strains. J. Protozool., 26, 613-615.

PERNIN, P., CARIOU, M. L. AND JACQUIER, A. 1985. Biochemical identification and phylogenetic relationships in free-living amoebas of the genus Naegleria. J. Protozool., 32, 592-603.

PERNIN, P. AND GRELAUd, G. 1989. Application of isoenzymatic typing to the identification of nonaxenic strains of Naegleria (Protozoa, Rhizopoda). Parasitol. Res., 75, 595-598.
SARGEaunT, P. G. 1985. Zymodemes expressing possible genetic exchange in Entamoeba histolytica. Trans. R. Soc. Trop. Med. Hyg., 79, 86-89.

SARGEAUNT, P. G., JACKSON, T. F. H. G., WIFFEN, S. R. AND BHOJNAN1, R. 1988. Biological evidence of genetic exchange in Entamoeba histolytica. Trans. R. Soc. Trop. Med. Hyg., 82, 862-867.

SMITH, M. Y. AND FRASER, D. 1976. Polymorphism in a cyclic parthenogenetic species: Simocephalus serrulatus. Genetics, 84, 631-637.

SONNEBORN, T. M. 1957. Breeding systems, reproductive methods and species problems in protozoa. In: Mayr, E. (ed.) The Species Problem. Am. Assoc. Adv. Sci. Symp., Publ. no 50. 155-324. Washington, DC.

STERnberG, J., TAit, A., HALEY, S., Wells, J.-M., LE PAGE, R. W. F., SCHWElZER, J. AND JENNl, L. 1988. Gene exchange in African trypanosomes: characterization of a new hybrid genotype. Mol. Biochem. Parasitol., 27, 191-200.

STEVENS, A. R., DE JONCKHEERE, J. F. AND WILLAERT, E. 1980. Naegleria lovaniensis new species: isolation and identification of six thermophilic strains of a new species found in association with Naegleria fowleri. Int. J. Parasitol., 10, 51-64.

TAIT, A. 1980. Evidence for diploidy and mating in trypanosomes. Nature, 287, 536-538.

TibayrenC, M., KJEllberG, F. AND Ayala, F. J. 1990. A clonal theory of parasitic protozoa: The population structures of Entamoeba, Giardia, Leishmania, Naegleria, Plasmodium, Trichomonas and Trypanosoma and their medical taxonomical consequences. Proc. Natl. Acad. Sci. USA, 87, 2414-2418.

WALLIKER, D., QUAKYl, I. A., WELlEMS, T. E., MCCUTCHAN, T. F., SZARFMAN, A., LONDON, W. T., CORCORAN, L. M., BURKOT, T. R. AND CARTER, R. 1987. Genetic analysis of the Human malaria parasite Plasmodium falciparum. Science, 236, 1661-1666.

WEIR, B. S. 1990. Genetic Data Analysis: Methods for Discrete Population Genetic Data. Sinauer Associates. MA. 